The following conclusions may be drawn from the present series of cases. Abscesses in the temporo-sphenoidal lobe, which is the most common situation, are often associated with an inflamed or sloughing dura mater over the anterior surface of the petrous bone, or with a collection of pus beneath it. Other complications are infrequent except meningitis, which is generally due to the extension or to the rupture of the abscess, which is almost always situated very close to the roof of the tympanum. A foul discharge is often a source of danger, and frequently, if not invariably, the spread of the mischief is due to imperfect drainage of the middle ear. Mastoid suppuration often infects the posterior surface of the petrous bone, but it may be associated with disease limited to the middle fossa of the skull. Cerebral abscesses only occur when the otorrhoea has lasted for months or years. The symptoms usually come on insidiously, being vague for a considerable time, which may be called the latent period; during this time headache, vomiting, and a slow dull mental condition are usually present. After a variable period the acute stage is entered upon, which may last less than a week; agonising headache is the most marked symptom, but it may not be noticed if the patient be very lethargic. The temperature is rarely high with uncomplicated cerebral abscess; it was not above the normal in six cases; in eight it was high, but three of these had meningitis, two thrombosis of the lateral sinus, and two niarked lesion of the dura mater. The pulse is often increased in rate, but when the abscess is large it may become slow and irregular. Tenderness of the scalp was not especially noticed. Rigors and pyrexia are not frequent in uncomplicated cases, but they both occur occasionally. A headache of intense severity and a dull, sluggish mental state are the two most characteristic symptoms. Optic neuritis is but infrequently noticed, and is often in such cases due to a complication.

The three cases of cerebellar abscess presented no very marked signs. They appear to be less common, and will be probably found associated with disease of the dura mater behind the petrous bone or with thrombus of the sinus.

There is no evidence, pathological or other, that cases of cerebral abscess ever recover without the aid of a surgeon, and although a few successful cases have been drained, even now almost every one is fatal. The objects to be aimed at in treatment are- $(a)$ In every case to improve the drainage of the ear by gouging away or trephining the mastoid sufficiently to open up the horizontal cells or antrum, where pus is often found, and to break a hole through the deeper part of the posterior wall of the external meatus, so as to allow no secretion to be retained. The cavity should be rendered aseptic as soon as possible, and in a case of otitis media this should be carried out as soon as there is evidence of a fresh accession of severe mischief; should further exploration be necessary later on, one great source of danger, the septic otorrhœea, will be much reduced. The external ear should be dressed apart from other openings, if any are made. (b) To expose the anterior surface of the petrous bone so as to allow free drainage for any pus or débris which may have formed in connexion with the dura mater, which is often inflamed or gangrenous. This is best reached at a point half an inch above the external meatus. Should there be any pus retained, some will often be found in the diploe of the bone removed, in which case the bone should be broken away to a quarter of an inch above and just in front of the meatus, so as to expose the most dependent part of the anterior surface $(c)$ to drain the abscess from below when possible. In the case of a temporo-sphenoidal abscess, the area beneath which it will almost universally be found may be said to be bounded anteriorly and posteriorly by curved lines drawn through the temporomaxillary joint and the middle of the mastoid, running at right angles to the sagittal suture and lying between half an inch to two inches above the meatus. The lower part of this area should therefore be explored with trocar and cannula after breaking the bone away, or trephining a fresh hole, unless special symptoms indicate that the abscess is higher. If the attempt to find pus is unsuccessful, the lateral sinus should be exposed half an inch behind the meatus and examined; if there is no extra-dural abscess and the sinus is healthy, the bone may be further broken away, and the outer and under part of the cerebellum explored for abscess. By this method all the likely seats for pus to accumulate can be systematically examined, and we give the patient the best chance. It is necessary to examine all these seats in doubtful cases, because, although in some uncomplicated instances we may be able to determine the lesion fairly definitely, yet where two or more lesions are combined the uncertainty in the diagnosis is so great that the best method is to explore all possible spots where pus may be collected.

Thrombosis of the lateral sinus occurred twenty two times. The condition both of the wall of the vein and of its contents varied. In some there was well-marked phlebitis; in considerably more than half the thrombus was suppurating, and in others, where not breaking down, it had set up a pulmonary pyæmia, thus demonstrating its septic nature. 'The disease more of ten spreads from the posterior wall of the middle ear than from the mastoid cells; this is important, for any treatment to be successful must deal with the condition of the bone and dura mater as well as with the sinus. Whenever the mastoid vein, which perforates an inch and a quarter behind the meatus and on a level with it, is found thrombosed, the sinus should be explored. The clot may be a small one or it may occupy the whole of the sinus and spread into the internal jugular or general venous system of the skull. Thrombosis is a fatal lesion, but there is some evidence that patients with the typical symptoms appear to recover, at any rate for a time. The otorrhoea is generally, but not always, of long standing; in only five it lasted less than seven weeks. The onset is usually sudden, the chief symptoms being pyrexia, rigors, pain in the occipital region and in the neck, associated with a septicæmic condition. Earache, as distinct from headache, is more common than with meningitis and abscess; vomiting and coma were also met with. In no other complication are erratic pyrexia and rigors so constantly present, and it will be always justitiable to assume that they probably indicate thrombosis in any patient in whom freely opening the deeper mastoid cells and draining the ear have not been. followed by their subsidence. Well-marked optic neuritis may be present, and is more suggestive of sinus thrombosis than of other lesions. The appearance of acute local pulmonary mischief or of distant suppuration is almost conclusive of thrombosis; and, as death in three-quarters of the cases ensues from pulmonary pyæmia after a course of but three weeks, treatment, to be of any value, must be directed to the prevention of the pysenia. When such a danger has to be combated we must be willing to run great risks in order to save some of the patients. The internal jugular vein should be ligatured in the neck, the lateral sinus should be opened, and, if the clot be very foul and septic, it may be scraped out, rendered aseptic as soon as possible, and, if desirable, irrigated. In some instances it may be better to ligature the jugular vein low down in the neck, seal the wound, then ligature and divide the vein higher up, the upper end being brought out so as to allow any septic material that may pass down to escape externally. This line of treatment, which may seem too heroic, has been recommended by surgeons, and carried out successfully, and only some such method can. avert the pulmonary infection which carries off these patients. This same treatment deals with the dura mater over the posterior surface of the petrous bone, which, if neglected, is a source of danger to nearly half its victims. If the lateral sinus, after it has been punctured, whether purposely or accidentally, be found to be healthy, thrombosis need not necessarily ensue. I have seen this happen three times, and no evil results followed, the patients dying from other causes.

\section{SUBACUTE INDURATIVE PNEUMONIA. ${ }^{1}$}

BY PERCY KIDD, M.D., F.R.C.P.,

ASSISTANT PHYSICIAN AND PATHOLOGIST TO THE BROMPTON HOSPITAD FOR CONSUMPTION AND DISEASES OF THE CHEST.

IT is not intended on the present occasion to discuss the subject of pulmonary induration in its general bearings, the object of this paper being to consider the group of cases in which fibrous changes in the lung are the direct sequel of a more or less acute pneumonia. Contradictory opinions have been expressed concerning the termination of acute lobar croupous pneumonia in induration. Some authorities, among whom are Rokitansky, Buhl, Wilks, and Wagner, deny that the acute classical pneumonia ever passes into a

1 Paper read at the Medical Society of Iondon, March 24 th. 
chronic stage. Others, including Stokes, Charcot, Marchand, and Ziegler, hold the existence of this sequence of events as proved. Quite recently Dr. Coupland recorded in the Transactions of the Pathological Society, vol. xxx., a case of chronic lobar pneumonia which he regarded as illustrating the transition of croupous pneumonia into fibrous induration of the lung. Within the last few years this question has been reopened by Wagner, ${ }^{2}$ Heitler, ${ }^{3}$ Talma, ${ }^{4}$ Hanau, ${ }^{5}$ and $\mathrm{Pal}^{6}{ }^{6}$ the general result of their observations going to show that the pneumonia which leads to induration is a special form, distinct from the acu te classical type.

I propose now to describe shortly two cases bearing on this question.

CASE 1.-H. WW —, aged forty-four, a cabman, was admitted into the Brompton Hospital on Nov. 29th, 1886, on account of shortness of breath and cough. Family history good. The patient stated that six years ago he had "inflammation of the lungs," and for years he had noticed a slight morning cough, but with these exceptions his health had been good until the present illness began. He admitted having drunk freely. Three months ago he was seized with sudden chills, weakness, and cough, and was confined to bed for two days. Since that time he had been ailing, with feelings of soreness in the chest, expectoration, shortness of breath, and night sweats, and three weeks ago he had an attack of diarrhoea lasting a few days. On Nov. 27th, three days before admission, his breath became shorter and his cough more troublesome, which he attributed to the recent fogs. The expectoration had never been rusty, but had been abundant throughout. On admis. sion the patient was found to be a fairly well-nourished man. Respiration laboured and wheezing; complexion slightly yellowish ; capillaries of the face injected. Pulse 126, large and dicrotous; temperature $103^{\circ}$; respiration 30 per minute. A superficial examination of the chest elicited dulness throughout the right side, with blowing breathing in the interscapular region, and sonorous rhonchi and small cracking râles were audible over both lungs. The diagnosis was acute pneumonia. A few days later dulness and loud bronchial breathing were present over the whole right lung, front and back, the adventitious sounds being less marked than at first. The sputum was abundant from the first, and shortly after admission it contained a little blood, but at no time was it rusty or characteristic of pneumonia. During the first twelve days the course of the disease was very aniform, and may be thus summarised: moderate pyrexia (the temperature generally varying from $102^{\circ}$ to $101^{\circ}$, on two occasions rising to $103^{\circ}$ ), a frequent pulse (120 to 140), rapid respiration $(40$ to 60 ), and nocturnal delirium. Four days before death the temperature suddenly fell to normal, sub. sequently fluctuating between that point and $101^{\circ}$, and a small quantity of albumen was now discovered in the urine. The patient continued to take nourishment well up to the last, death occurring suddenly from syncope early on Dec. 16th.

Summary of the post-mortem examination.-The right pleural cavity was obliterated by soft adhesions. The left pleura was healthy. The heart weighed $14 \mathrm{oz}$., the right side being dilated; muscle generally pale and soft; valves healthy. Aorta very atheromatous. The right lung was solid throughout, the upper lobe of pale-grey colour with irregular pigmentation, the lobules being clearly marked out in places. Towards the apex there were two small cavities of the size of hazel nuts, surrounded by softened lung tissue. The lower lobe was red, granular on section, and softer than the upper lobe. The left lung was cedematous, one small calcareous nodule in the lower part of the upper lobe, but no other disease. The liver was large and fatty, the kidneys pale, and the spleen contained an infarct. The pia mater over the cortex was thickened. The brain and all other organs were healthy.

On microscopical examination of the right lung the red consolidation affecting the lower lobe was seen to consist almost exclusively of intra-alveolar products. The alveoli contained roundish masses of a coarsely granular opaque material, in which a few nuclei were visible. In places these plugs at their centre showed a delicate meshwork of fibrinous threads, and in rare instances consisted mainly of fibrinous matter. In every case, however, the alveolar plugs were ensheathed in a more or less complete investment of young connective tissue, separating them from the

Deutsch. Arch. f. Klin. Med., Bd. xxxiii.

4 Zeitschr. f. Klin. Med., Bd. x. ${ }_{6}{ }^{5}$ Foid., Bd. xii. alveolar walls. These sheaths were composed of a faintly fibrillated layer of varying thickness, interspersed with scanty fusiform and round nuclei, and separated in most cases from the alveolar walls by a space containing desquamated epithelial cells, though here and there fusion had occurred. In many cases the sheaths in neighbouring air sacs were connected by delicate fibrous processes, in which occasionally a central fine opaque filament could be recognised, representing a communication between corresponding opaque alveolar masses. Scanty capillary bloodvessels could be traced in the intra-alveolar connective tissue capsules, and in some instances they were clearly connected with the capillary network in the walls of the vesicles. The condition of the alveolar passages or infundibula was very difierent from that of the air sacs. In almost every instance the infundibula were filled with recent fibrinous exudation containing a few leucocytes and red blood-corpuscles, without any connective tissue investment. The interstitial tissue showed a slight diffuse thickening, but this change was insignificant as compared with the intra-alveolar growth, and in the case of the alveolar walls the thickening consisted almost exclusively of a small-celled infiltration of no great dimensions. In the grey consolidation of the upper lobe, a more advanced stage of the same condition was found. The air sacs were stuffed with rounded masses of connective tissue, con sisting of a central core of round and spindle cells, with a meshwork of delicate fibres surrounded by a more distinctly fibrous outer zone. Connexion with the alveolar walls had taken place in many but not in all instances, and only in a few vesicles could any pulmonary epithelium be discovered. Numerous capillaries were seen in the alveolar contents, especially in the more fibrous plugs. Traces of the opaque granular substance representing altered fibrin were with difficulty recognised in a very few vesicles, but no distinct fibrinous matter. The interstitial thickening was more pronounced than in the case of the lower lobe, but was relatively slight, so that the outlines of the alveoli could always be made out. The pleura was fibrous and thickened both over the lower and upper lobe. No microorganisms could be detected in the sections examined. The muscular fibres of the heart showed no recognisable change.

CASE 2. - Thomas H- aged fifty-one, potter's sampler, was admitted to hospital on Feb. 26th, 1889, under the care of Dr. Tatham, whom I have to thank for permission to publish the case. Family history good. The patient said that he had never had pleurisy, inflammation of the lungs, hæmoptysis, or rheumatism, and had enjoyed good health till the present attack. Three weeks before he "caught cold in the damp," but " took no notice of it at first." Soon, how ever, he began to suffer from cough, expectoration, shortness of breath, and slight shiverings; but the illness did not begin with a shivering attack. Shortly afterwards the expectoration became blood-stained. About a week ago "herpes" appeared on his lips. The patient had been confined to his bed almost from the first-i.e., about three weeks, but till then he had been at work. His wife supplemented this account by a statement that although her husband had not suffered from any cough or pulmonary symptom until three weeks previously, he had not appeared to be in his usual health for some short time. On admission, the patient was a spare, rather poorly-nourished man, with remains of herpes about the nose. Temperature $99^{\circ}$. Physical examination disclosed dulness on percussion over the whole right back, becoming absolute at the base, with weak breath sounds, indistinct crumpling and crackling râles, and feeble vocal fremitus and resonance over the same area. In front there was dulness from the fourth rib downwards, but the breath sounds were not altered. On the left side a few crackling râles were heard in the subscapular region, but no other abnormal signs. The diagnosis was "thickened pleura; (?) new growth." An exploratory puncture gave a negative result. The sputum, which was scanty and of a dirty greyish colour, contained no tubercle bacilli. The temperature was very irregular, generally ranging from $90^{\circ}$ to $100^{\circ}$, but sometimes falling to normal for a few days. Diarrhcea was a troublesome feature throughout. During the first fortnight a temporary improvement took place, but towards the end of March the sputum became very foul and almost gangrenous in odour. About the same time albuminuria and enlargement of the liver appeared, the general condition began to deteriorate, and the physical signs in the chest underwent a change Tubular breathing and bronchophony were now heard at 
the angle of the right scapula, and at the left base dulness and crackling sounds had developed. Putrid expectoration and albuminuria persisted, and with oedema of the legs, hectic fever, increasing dyspncea and prostration, the patient sank on May 9 th, four months after the onset of his illness. Summary of the post-mortem examination.-Right lung adherent to the chest wall throughout by dense fibrous adhesions. The lower lobe posteriorly converted into a large cavity with ridged walls, but smooth lining membrane of dirty red colour, containing a putrid brownish fluid. The anterior part of this lobe much contracted, of whitish colour and very tough. Middle lobe of coalblack colour, tough, and quite airless. Upper lobe large, œelematous, irregularly pigmented, and very firm, but the consolidation was not quite uniform, patches of aerated lung tissue alternated with foci of induration. Interlobar septa greatly thickened. The left lung was loosely adherent throughout. The lower lobe closely resembled the right upper lobe, showing the same marbling and patchy consolidation, with a few minute foci of softening in the midst of some pinkish-grey patches of consolidation. The upper lobe marbled and odematous, with a few ill defined, stellate, blackish, fibrous patches here and there. The inter-lobar soptum was thickened slightly. The bronchial mucous membrane presented a dull livid colour, but there was no dilatation of the bronchi in either lung. In the larynx there was one small ulcer over the right "processus vocalis." In addition the following morbid conditions were found: parenchymatous nephritis, with slight amyloid disease of the glomeruli, amyloid degeneration of the gastro-intestinal mucous membrane, and nutmeg liver.

Microscopical examination of the lower lobe of the right lung showed a firm fibrous growth which had obliterated all traces of the pulmonary structure. The middle lobe exhibited a well-marked condition of chronic interstitial pneumonia-viz, fibrous thickening of the alveolar walls and of the inter-lobular, peri-bronchial, and peri-vascular tissue. In the right upper lobe and the left lower lobe there were numerous patches of small-celled exudation into the alveoli and bronchial tubes with foci of necrosis, and scattered fibrous thickening, peri-bronchial and peri-vascular. The laryngeal ulcer showed no tubercular character, and no tubercle bacilli were found in its floor or in the contents of the pulmonary cavities.

The first was clearly a case of lobar pneumonia terminating in induration, the induration being the result of organisation of a fibrinous alveolar exudation. Microscopically, all stages in the process of organisation could be traced, the appearances closely resembling those described by Dr. Coupland and other observers. The pathogeny of the disease is less evident. A consideration of the history seems, however, to prove that this was not an instance of acute classical pneumonia ; for although the sharply defined onset, with rigors, cough, and prostration, reminds one of the latter disease, the constitutional disturbance was too slight and transitory to justify us in adopting this view. According to the patient's express statement, he was only confined to bed for two days, though feeling ill afterwards, which fact alone would suffice to preclude the existence of acute sthenic pneumonia. The clinical course of the disease and the anatomical condition of the lung warrant the description of the case as one of a subacute progressive indurative pneumonia.

In the second case, in which the patient came under observation three weeks after the attack began, the onset of symptoms, though not so acute as in the first patient, was nevertheless clearly defined, and the illness was sufficiently severe to compel him to keep his bed from the first. In contradistinction to the previous case, the indurative process here was essentially interstitial. In both instances the pneumonia was lobar. In both, necrosis occurred in the indurated tissue without the intervention of bronchial dilatation, but excavation developed at an earlier date and played a more important part in the last case. Putrescence of the cavity secretions, no doubt, will account for the developnıent of secondary broncho-pneumonia and putrid bronchitis, which, in combination with nephritis, must be regarded as the direct cause of death.

For clinical purposes the two cases may be grouped together, agreeing as they do in many important particulars, especially in their subacute progressive character and in their termination in induration. At the same time the different localisation of the fibrous growth may depend on a difference in etiology; but as to the exact cause of this form of pneumonia nothing as yet is known. In Hanau's case, bacteriological investigations were not attended with any positive result. The question whether acute croupous pneumonia ever leads to cirrhotic changes is a difficult one to answer; and, in the absence of any decisive bacteriological or other test for the presence of this disease, we cannot expect the solution of the difficulty at present. It is probable that this sequence of events is far rarer than some authors state, and Heitler hints with considerable probability that some cases at least of pulmonary induration, gangrene, or abscess that have been recorded as depending on acute sthenic pneumonia were really specimens of the subacute indurative variety now under consideration. Wagner and Heitler both point to the fact that in the acute classical pneumonia signs of infiltration may persist for months, and finally be succeeded by perfect resolution, as showing that the pulmonary exudation is not possessed of any specially irritant properties. Among those who have done most to differentiate the indurative form of pneumonia Heitler certainly deserves the chief credit. His two papers, based upon five cases, contain most valuable remarks on the pathology and diagnosis of this disease, which he prefers to call "primary parenchymatous pneumonia," adopting a term suggested originally by Buhl.

A review of the cases lately recorded establishes the following facts, most of which have been emphasised by Heitler. The patients attacked were, as a rule, free from previous pulmonary disease, though in one or two instances evidence of chronic alcoholism was obtained. The development of the disease is more or less acute and well defined. the symptoms being fever, dyspncea, cough, prostration, and frequently, though not always, rigors; but the constitutional depression is much less narked than in acute pneumonia. In Hanau's case the onset was very insidious, though, as the patient was demented, this observation does not invalidate the general truth of the previous statement. Pyrexia is irregular and of moderate degree, the temperature rarely exceeding $102^{\circ}$. The sputum is not rusty, and commonly becomes putrid as the case progresses, owing to the supervention of necrotic changes in the lung, and is then almost a conclusive proof of the presence of cavities, even in the absence of other signs. Retraction of the chest wall has been seldom observed; but, according to Heitler, when it occurs it is pathognomonic. The absence of this sign probably depends on the subacute course which nearly all the cases ran. The consolidation is lobar, or may invade the whole of one lung, in which case the different lobes are apt to be involved in successive stages.

Necrotic excavation of the lung is very common, the cavities being ragged and gangrenous, or encapsulated, according to the duration of the case. Secondary septic broncho-pneumonia and putrid bronchitis are apt to supervene from inhalation of the contents of the cavities. Bronchial dilatation is either absent or slight. Thickening and adhesion of the pleura are invariable. The cases end fatally from dilatation of the right heart and cardiac failure, septic infection, or renal complications. All the cases now referred to have succumbed in periods varying from five weeks to nine months, but it is probable that the disease may become partially arrested and lapse into a very chronic stage. Some of the instances of pulmonary cirrhosis or chronic pneumonia that we meet with would certainly bear this interpretation.

Heitler goes at great length into the subject of diagnosis; but reference to the cases recorded by other observers demonstrates that some of the differential points on which he insists would not have given much assistance in some instances. If the patient should be seen at an early period, it may be difficult at first to exclude acute pneumonia in the stage of resolution; but, as Heitler remarks, the progress of the case would soon decide the point. For in this affection the physical signs and general condition change rapidly, which is not the case in the indurative type. More difficulty is likely to be experienced in diagnosing the present form from acute croupous pneumonia in the stage of retarded resolution, but in the latter case, as the same author points out, the general condition steadily improves and the temperature declines, in spite of the persistence of pulmonary consolidation. In the indurative type, on the other hand, the temperature keeps up, and the constitu. tional state gradually, but steadily, deteriorates. The sharply defined onset of the disease would almost exclude any form of tuberculosis, but the development of putridity of the sputum, coupled with the absence of tubercle 
bacilli, would leave little room for doubt on this score. The absence of any previous chronic disease of the lung should preclude the existence of bronchiectasis or abscess.

In conclusion, we may affirm the existence of a subacute lobar pneumonia distinct from the acute classical type, characterised by a tendency to fibrous and necrotic changes in the lung. The indurative process may be mainly or exclusively interstitial, it may be represented wholly or in part by organisation of an alveolar exudation, or it may comprise both of these lesions. It is possible that these anatomical differences imply a corresponding difference in etiology; but further analysis is not as yet in our power, and, for clinical purposes, both forms nay be included under the title "indurative pneumonia," which indicates the characteristic feature common to each.

\section{SCIENTIFIC STUDY OF THE CONDITION OF CHILDREN IN SCHOOLS.}

By FRANCIS WARNER, M.D.LoND., F.R.C.P.ENG., PHYSICIAN TO THE LONDÓN HOSPITAL, AND LECTURER ON MATERIa MEDICA AND THERAPEUTICS AND ON BOTANY.

I PROPOSE to consider the possible value of accurate observation of facts seen in children in schools, as a means of aiding the solution of educational problems and assessing the value of educational work and certain possible means of improving it. It is needless to argue that public benefit has resulted from the employment of scientific methods in connexion with sanitation, food supply, manufacture, travelling, \&c., while some training in science is now thought necessary for the workers in many trades. In education the teaching of science subjeets is justly valued as a means of producing mental culture. The professions of law, the army, and art do not ignore aid from science; why should not the professional teacher have the benefit of precise knowledge as to the bodily and brain condition of his pupils-the material upon which he works? There is at present but little accurate scientific observation of children in schools, from the point of view of ascertaining their special adaptations to and requirements in education. It remains for our profession to systematise the scientific study of children from the point of view of methods of education, and to put such results before teachers and others responsible for national and private education. In systematising such scientific work as it may be conducted in a large school, without use of the processes of the consulting.room, only methods of observation by sight can conveniently be employed. What signs shall we note, and what relative value is to be assigned to each? Looking upon a body of children as pupils in a school, we would wish to classify them according to their (1) development, (2) nutrition and physical health, (3) brain condition. The grosser forms of low development of the body have many times been ably described by many authorities on imbecility, and the relative value of various defects of skull, the features, \&c., has been fairly determined ; all these may be seen in less degree in school children. I will not dwell further on this group of signs now. As to indications of the brain condition, these may be observed with equal facility by noting the balance and action in the various mobile features and parts of the body. Having previously fully described these signs in works published, $1 \mathrm{I}$ will not attempt even to epitomise them here; they may easily be learned by any observer; but, like all new physical signs, they require some moderate degree of application to recognise them. It is not, however, my desire at present to urge any one system for use in observing children in schools, but to $d$ well on the importance of obtaining scientitic knowledge as to the physical and brain condition of our school population. The late Royal Commission on Blind, Dumb, and Exceptional Children could obtain no body of statistics as to pupils in school, showing how many were defective or feeble in brain, ill-developed, ill-nourished, nervous, mentally dull, or epileptic, \&c. There are 6,000,000 children in schools under the control of the Education Department. How many are

1 The Children : How to Study Them. F. Hodgson, \&9, Farringdonstreet, E.C. Lectures on the Growth and Means of 'Training the Intellectual Faculty. Cambridge C'niversity Press. unfitted for education under the code, who are of low-class make, the percentage of nervous children in the schools, and the distribution of each class? These are questions worthy of investigation. The effects of education and various modes of teaching upon the brains of the children can only be determined by actual observation in the schools. We have large bodies of statistics bearing upon disease, its causation and distribution, and upon pauperism, crime, non-employment, \&c., but there is no body of facts founded upon extended observation of school children showing their condition, and its bearing upon the adult population of the next decade. What is wanted is a careful investigation conducted by observation of the children along definite lines, as well as by inquiry of the teachers. It is only by an extended body of facts obtained in various schools and in different localities in town and country that the average condition of children can be known. I think, from my own observations, that there are more nervous, over-mobile children in London than in northern towns, and fewest cases among the resident pauper schools, while the latter and certified industrial schools contain a high percentage of low conditions of development. At present we have no standard to go by, no average of the conditions we desire to remove. It is desired by all educationists that educational methods should be adapted to the special requirement of the school. The corporate character of a school depends upon the per* centage of the different classes of pupils present; similar methods are not adapted for a school with 10 per cent. nervous children, and 1 per cent. of cranial abnormalities, as compared with another school with $2 \cdot 7$ per cent. nervous children, and 4 'l per cent of cranial abnormalities. (Compare in report quoted Stockwell Practising School and Hanwell National School.) The efforts of a few medical men have produced a report ${ }^{2}$ of the condition of nineteen schools containing about 6000 children; this illustrates, better than any summary I can give here, the kind of information that such inquiry may elicit, and the uses to which it may be put. The study of pathology and clinical diagnosis must precede scientific treatment, and we need some exact knowledge of the condition of samples of the school population before science can take its proper place in directing education, or give due service to the State by advice upon many of the practical problems put forward by the educationist for solution.

Prince of Wales-terrace, Irensington Palace, W.

\section{NOTE ON A CASE IN WHICH THE ILIUM WAS TREPHINED FOR ILIAC ABSCESS.}

Br A. F. MCGILL, F.R.C.S., PROFESSOR OF SURGERY IN THE YORISHHRE COLLEGE.

THE following note shows the good effect which may follow trephining the ilium in suitable cases. Cases of this description are not, however, common. The practice may be expected to be useful when a collection of pus exists under the iliac fascia, and when this collection is circumseribed and limited to the fossa. Pus in this position, when left untreated, will probably pass under Poupart's ligament, and point in the upper part of the thigh extended to the femoral vessels, thus simulating psoas abscess. If they are now opened, or if they burst, a long sinus will be left which will take a considerable time to heal. The direct opening made in the case about to be mentioned apparently avoided this complication, and led to a speedy cure. Possibly this treatment may be of use in cases of abscess in the iliac fossa above the fascia; but I think this is doubtful. The experience of one case is not of much value, but as the treatment adopted is novel, it is given for what it is worth. I am indebted to my house surgeon, Mr. J. J. Mitchell, for the following notes.

C. A-, aged eighteen, was admitted into the Leeds Infirmary, under the care of Mr. McGill, on May 6th, 1889, complaining of pain in the right iliac region and right thigh. In $1884 \mathrm{Mr}$. McGill excised her right hip.joint for disease of long standing. She recovered quickly after the operation,

2 Report of a Committee of the British Pedical Assoriation on observation of Children in Primary Schools. Published by the Cam. bridge Cniversity Press. 